\section{Energy option}

\section{Amit Kumar and Nathan Lewis}

Harnessing Solar Power: The Photovoltaics Challenge. By Ken Zweibel. Plenum: 1990. Pp.310. \$29.94.

AT present, photovoltaic power provides an insignificant fraction of the world's energy supply. Some devoted followers of the field feel that this will change dramatically, but others feel that photovoltaics will never be a significant terrestrial power source. The optimistic viewpoint, put forward very competently by Zweibel in his recent book, is that as production costs become lower, and as issues such as pollution, global warming and scarcity of fossil fuels come to the forefront of public awareness, the impact of photovoltaic current and projected efficiencies, are described for each of these materials with enough clarity that the layman will be able to obtain a good grasp of the status of photovoltaics. This type of clear, concise analysis is also presented for other issues associated with photovoltaics, such as concentrator versus nonconcentrator systems, active versus passive systems, geographic location, and so on.

Furthermore, the text deals directly with many misconceptions that society holds about photovoltaics. Many feel that photovoltaics is not one of our primary energy options. Others feel it will save the world, and wonder why photovoltaic systems have not become commonplace. Zweibel's very thorough economic analysis based on current technology does a great deal to clear up these misconceptions. Additionally, his quantitative projections, economic and technical,

\section{IMAGE UNAVAILABLE FOR COPYRIGHT REASONS}

\section{All at sea}

\section{H. Charnock}

The Ocean in Human Affairs. Edited by S. Fred Singer. International Conference on the Unity of the Sciences (distributed by Paragon House): 1990. Pp.374. $\$ 34.95$.

AN unusual publisher - according to the flyleaf "the International Conference on the Unity of the Sciences (ICUS) convenes international, distinguished scientists and scholars to pursue academic discussion of theoretical and practical concerns. ICUS seeks an integrated world view based on absolute values generated through multi-disciplinary, academic dialogue". ICUS is generously sponsored by the Reverend Sun Myung Moon's Unification Church.

The tangible result of this high-level conversation is a series of books, of which The Ocean in Human Affairs is one. It is not stated but it seems to consist of papers presented at a conference held, as judged from most of the references, in 1985 or 1986. There are 21 chapters of which seven are commentaries on earlier contributions: they cover a wide range of topics, roughly equally divided between ocean science, exploration technology, ocean resources and ocean commerce. The editor attempts a linking introduction but the essays are too various, in subject and treatment, to relate to one another in any constructive way.

The papers in the section on ocean science are concerned with the ocean in relation to climate. S. I. Rasool notes that the presence of liquid water on Earth and the subsequent cvolution of life has stabilized its climate for the last three billion years. Because it has stabilized it within a range suitable for the survival of living organisms one might have expected some reference to the Gaia hypothesis and to the Anthropic Principle but the author confines himself to comparison with Venus and Mars. An article by A. Lerman on biogeochemical cycles has some relevance, as does another by $\mathrm{H}$. Oeschger entitled 'Long-term Climate Stability: Environmental System Studies' which deals particularly with the effects of atmospheric carbon dioxide. He points out that there is not much reason to believe that feedbacks in the climate system are such as automatically to limit the consequences of human interference, a conclusion perhaps more widely accepted now than when he presented his paper. The role of the ocean in climate fluctuation is discussed in a scholarly and dispassionate way by E. B. Kraus. Again much work has been done on this subject in recent years but Kraus does well to emphasize the random nature of climate
Amit Kumar and Nathan Lewis are at the California Institute of Technology, Division of Chemistry and Chemical Engineering, Pasadena, California 91125, USA. 